\title{
Cellular Localization of Carbonic Anhydrase Nce103p in Candida albicans and Candida parapsilosis
}

\author{
Jiří Dostál ${ }^{1}$, Jan Blaha ${ }^{1,+}{ }^{\dagger}$, Romana Hadravová ${ }^{1}$, Martin Hubálek ${ }^{1}$, Olga Heidingsfeld ${ }^{1,2}$ and \\ Iva Pichová ${ }^{1, *}$ \\ 1 Institute of Organic Chemistry and Biochemistry of the Czech Academy of Sciences, Flemingovo náměstí 2, \\ 16610 Prague, Czech Republic; jiri.dostal@uochb.cas.cz (J.D.); jan.blaha.18@ucl.ac.uk (J.B.); \\ hadravova@uochb.cas.cz (R.H.); hubalek@uochb.cas.cz (M.H.); olga-hh@uochb.cas.cz (O.H.) \\ 2 Department of Biochemistry, Faculty of Science, Charles University in Prague, Hlavova 2030, 12843 Prague, \\ Czech Republic \\ * Correspondence: iva.pichova@uochb.cas.cz \\ † Current address: University College London, Gower St, London WC1E 6B, UK.
}

Received: 17 December 2019; Accepted: 24 January 2020; Published: 28 January 2020

check for updates

\begin{abstract}
Pathogenic yeasts Candida albicans and Candida parapsilosis possess a ß-type carbonic anhydrase Nce103p, which is involved in $\mathrm{CO}_{2}$ hydration and signaling. C. albicans lacking Nce103p cannot survive in low $\mathrm{CO}_{2}$ concentrations, e.g., in atmospheric growth conditions. Candida carbonic anhydrases are orthologous to the Saccharomyces cerevisiae enzyme, which had originally been detected as a substrate of a non-classical export pathway. However, experimental evidence on localization of $C$. albicans and C. parapsilosis carbonic anhydrases has not been reported to date. Immunogold labeling and electron microscopy used in the present study showed that carbonic anhydrases are localized in the cell wall and plasmatic membrane of both Candida species. This localization was confirmed by Western blot and mass spectrometry analyses of isolated cell wall and plasma membrane fractions. Further analysis of C. albicans and C. parapsilosis subcellular fractions revealed presence of carbonic anhydrases also in the cytosolic and mitochondrial fractions of Candida cells cultivated in shaken liquid cultures, under the atmospheric conditions.
\end{abstract}

Keywords: carbonic anhydrase; Nce103p; Candida albicans; Candida parapsilosis; localization; cell wall; electron microscopy; mass spectrometry

\section{Introduction}

The yeasts Candida albicans and Candida parapsilosis can cause opportunistic infections in humans, especially in hosts whose immune defenses have been weakened. Candida species are involved in a range of diseases and are leading causative agents of invasive, life-threatening bloodstream infections. C. albicans is responsible for the vast majority of diseases caused by yeasts. C. parapsilosis is less virulent than C. albicans, but it ranks as the second or third most frequent pathogenic Candida species in global epidemiological studies. It often causes infections in low-birth weight infants at neonatal intensive care units [1-3].

Both C. albicans and C. parapsilosis thrive under a wide range of conditions and can metabolically adapt to environmental changes. This metabolic response includes adaptation to changing concentrations of ambient $\mathrm{CO}_{2}$. C. albicans cannot survive in atmospheric air, which contains approximately $0.04 \% \mathrm{CO}_{2}$, without expression of the carbonic anhydrase CaNce103p [4,5]. Carbonic anhydrases (CA) catalyze rapid reversible hydration of carbon dioxide into bicarbonate $\left(\mathrm{CO}_{2}+\mathrm{H}_{2} \mathrm{O} \leftrightarrow\right.$ $\left.\mathrm{HCO}_{3}{ }^{-}+\mathrm{H}^{+}\right)$. Although this reaction proceeds spontaneously in nature, its catalysis by CAs helps to maintain cellular $\mathrm{pH}$ homeostasis and to control a pool of bicarbonate, which is the substrate for 
metabolic carboxylation reactions. CA (EC 4.2.1.1) thus plays a vital role during the yeast colonization of the host skin or biofilms formation on abiotic surfaces such as plastic medical devices. When $C$. albicans enters the bloodstream, the $\mathrm{CO}_{2}$ concentration increases up to $5 \%$, and $\mathrm{CA}$ is transcriptionally downregulated [6,7].

Tight control of the $\mathrm{CO}_{2}$ fixation reaction is of such general importance that CAs arose in nature independently several times during evolution, yielding structurally different enzymes that are categorized into seven classes: $\alpha, \beta, \gamma, \delta, \zeta, \eta$, and $\theta$. The yeast CAs characterized thus far belong to the $\beta$-class [8]. CAs from $C$. albicans and Saccharomyces cerevisiae have been structurally characterized $[9,10]$ and their indispensability for these yeasts under the atmospheric growth conditions has been demonstrated $[4,11]$.

CA of S. cerevisiae was first discovered as one of the proteins that lacked classical secretion signal (SS) and was exported from the yeast cells whose standard secretory pathway has been blocked [12]. The gene name NCE103 refers to the non-classical protein export pathway. The orthologous genes were identified in C. albicans and C. parapsilosis are also denominated NCE103 [4,13]. CAs from C. albicans and C. parapsilosis will be referred to as CaNce103p and CpNce103p, respectively.

Nce103p enzymes are thought to play a role not only in $\mathrm{CO}_{2}$ hydration, but also in $\mathrm{CO}_{2}$ sensing and yeast cell signaling. Thus, changing levels of $\mathrm{CO}_{2}$ are related to morphology changes in C. albicans and contribute to virulence [7]. However, cellular localization of CaNce103p has not been examined. The emerging pathogen C. parapsilosis is generally less characterized than C. albicans, and CpNce103p has not been experimentally studied at all. In the present study we used immunoelectron microscopy, subcellular fractionation and mass spectrometry, to analyze cellular localization of CAs of two pathogenic Candida species.

\section{Results}

\subsection{Localization of Candida CAs Using Immunogold Labeling and Electron Microscopy}

C. albicans and C. parapsilosis CAs share $72 \%$ of identity. The polyclonal antibodies raised against recombinant CpNce103p were found to cross-react with recombinant CaNce103p (Dostál 2019, unpublished results) and were thus instrumental for the localization of CAs in both yeast species studied using electron microscopy and immunogold labeling technique. Figure 1 shows that CAs are predominantly localized in the outer part of the cells, in the cell wall (CW) and plasma membrane (PM) but also in the cytoplasm. The PM localization is visible especially in C. albicans. Immunogold labeling detected also populations of Nce103p molecules secreted from C. albicans or C. parapsilosis.

\subsection{Mass-Spectrometry Analysis of CW and PM Fractions}

To confirm the subcellular localization of CAs, the CW and PM fractions from both Candida species were isolated using the protocol of Zinser and Daum [14] and proteins released from these fractions were analyzed by Western blot with anti-CpNce103 antibodies and mass spectrometry (MS). As illustrated by Figure 2A, CAs were detected in the CW fractions of both yeast species. However, only the PM fractions obtained from C. albicans displayed a weak signal that may correspond to the $\mathrm{CA}$, which is in an agreement with the EM observations. 


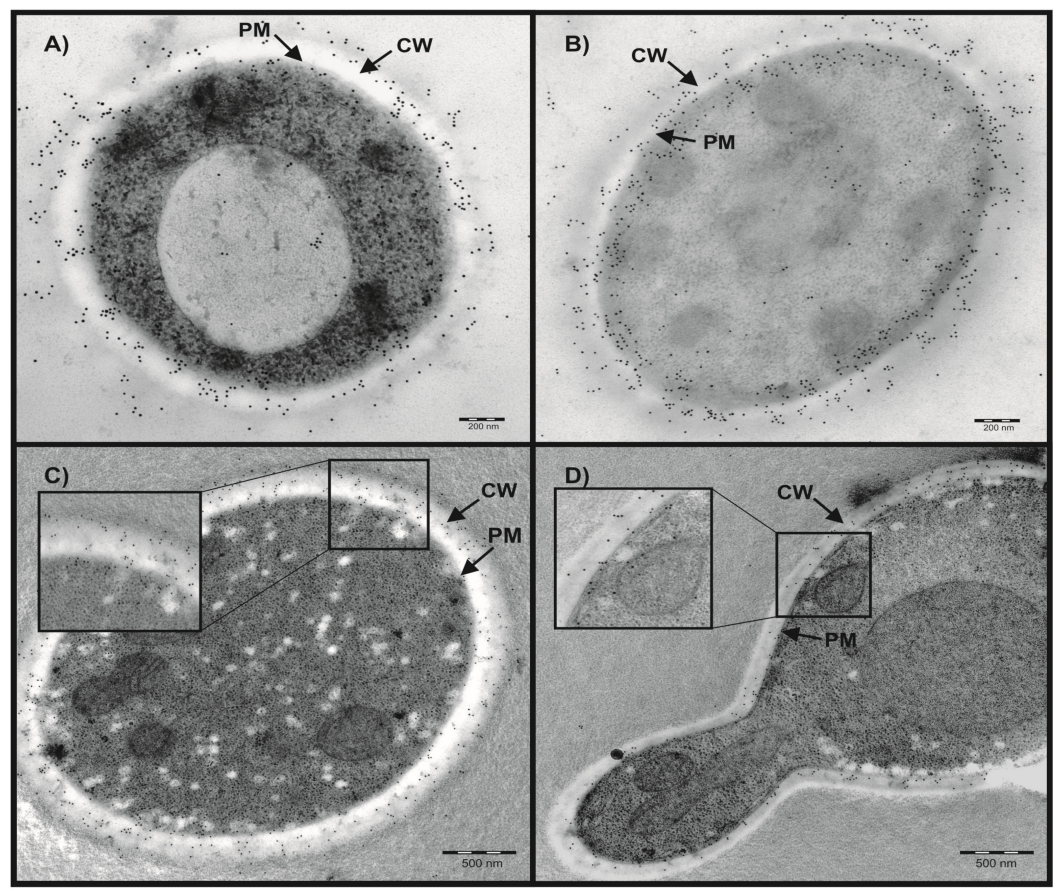

Figure 1. Localization of Nce103p using immunogold labeling and electron microscopy. (A,C) C. parapsilosis; (B,D) C. albicans; CW: cell wall, PM: plasma membrane. Scale bars, $200 \mathrm{~nm}$ and $500 \mathrm{~nm}$. Panels C and D contain also zoom-in sections of the outer parts of the cells.

A)

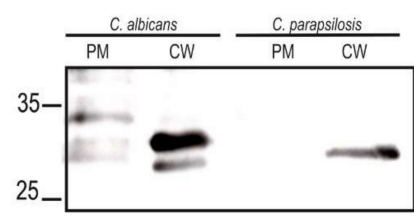

B)
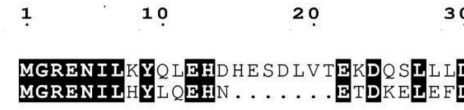

40

CaNce103p

CaNce103p

I
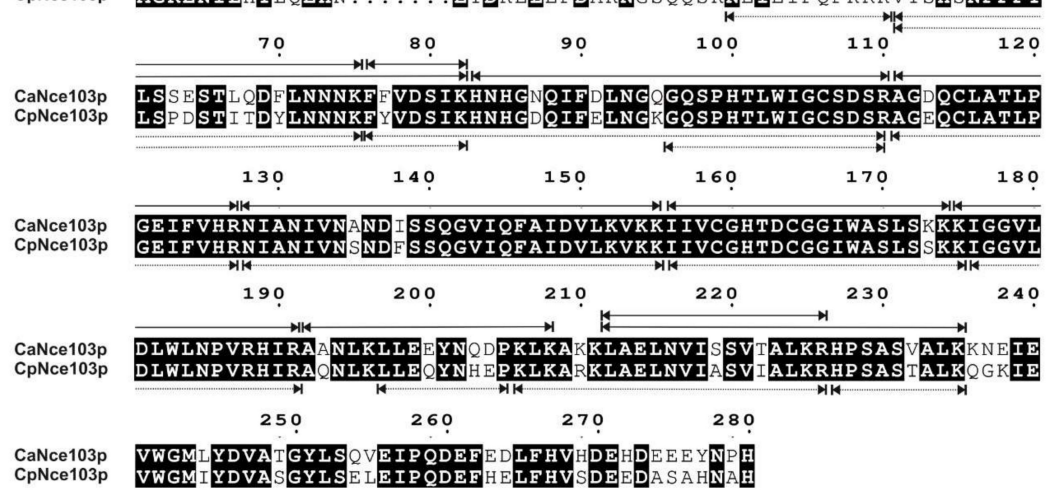

Figure 2. Analysis of Nce103p presence in PM and CW fractions of C. albicans and C. parapsilosis. (A) Western blot analysis of PM and CW fractions obtained using the protocol of Zinser and Daum [14]. CAs were detected using polyclonal rabbit antibodies against CpNce103p, diluted 1:1000. (B) Mass spectrometry (MS) analysis of CaNce103p and CpNce103p in C. albicans and C. parapsilosis CWs. The conserved amino acids are highlighted in black. Peptides detected by MS analysis are marked with arrows above (CaNce103p) or below (CpNce103p) sequences (CpNce103p, UniProtKB: G8B6R8 and CaNce130p, UniProtKB:Q5AJ71). 
MS analysis confirmed the presence of CAs in the PM and CW of both C. albicans and C. parapsilosis cells. The sequence coverages of PM and CW released proteins using the method that involved SDS, $\beta$-mercaptoethanol, and heating were $69 \%$ for both CaNce103p and CpNce103p (Figure 2B). The identified peptides in CaNce103p and CpNce103p are summarized in Tables S1 and S2, respectively.

\subsection{Western Blot Analysis of Selected Subcellular Fractions}

According to electronic annotation listed in the Candida Genome Database, both CaNce103p and $\mathrm{CpNce103p}$ were predicted to be localized in the mitochondrial intermembrane space (www. candidagenome.org; 10th December 2019) [13]. In order to examine the presence of CAs in mitochondria and cytosol, mitochondrial and cytosolic fractions were prepared from both C. albicans and C. parapsilosis, and subjected to the Western blot analysis. The first step in the yeast subcellular fractionation was preparation of spheroplasts, which was based on enzymological removal of the cell wall. Lyticase treatment of the cells yielded the protein fraction (LRP), which was used as an alternatively prepared $\mathrm{CW}$ protein fraction and analyzed along with the mitochondria and cytosol. As shown in Figure 3, Western blots for C. albicans and C. parapsilosis. displayed similar pattern, detecting approximately $16 \%$ of total Nce103p proteins in mitochondria of the both yeast species. CAs occurred also in cytosol, but predominantly among the proteins released from the CW using lyticase. Roughly $48 \%$ of total CaNce103p and 59\% of CpNce103p were detected in the LRP fraction.

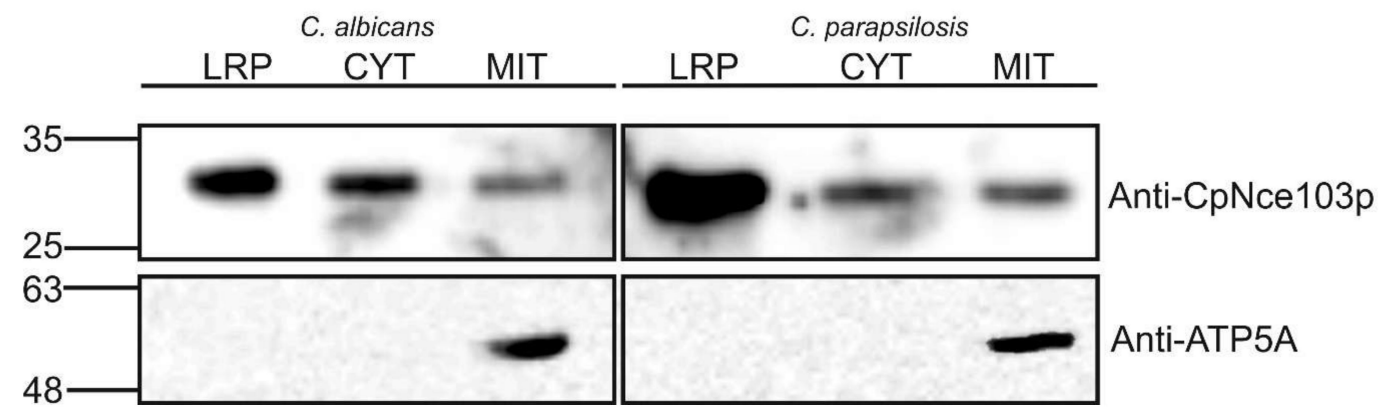

Figure 3. Western blot analysis of CA presence in C. albicans and C. parapsilosis mitochondrial (MIT) and cytosolic fractions (CYT), and in the fraction obtained by the lyticase treatment of the cell was (LRP). Polyclonal anti-CpNce103p antibodies (upper panel) and anti-ATP5A antibodies (lower panel) were used for the detection.

Anti-ATP5A antibodies were used as the mitochondrial marker, to confirm the identity of the mitochondrial fraction and to verify absence of mitochondria in the CYT and LRP fractions.

\section{Discussion}

Adaptation to changing $\mathrm{CO}_{2}$ concentrations is one of the key and vital abilities of all living cells. C. albicans and C. parapsilosis regularly occur in the environments, in which the $\mathrm{CO}_{2}$ concentrations differ by two orders of magnitude, and require carbonic anhydrases to survive under the atmospheric growth conditions. The gene NCE103 encoding carbonic anhydrases in both Candida species studied received its name on the basis of homology with the $S$. cerevisiae gene encoding a non-classical export protein, which was secreted from the cells by a non-classical pathway and lacked a signal peptide [12]. In silico SS prediction using SignalP 4.1 [15] showed the absence of a regular SS in CaNce103p and CpNce103p, similar to their Saccharomyces ortholog. In the present work, both CAs were detected in the CW using diverse methodological approaches. CaNce103p and CpNce103p may thus be substrates of the non-classical export pathway in the respective yeast species. According to Cleves et al. [12], non-classical protein export could play a role in removal of proteins that are normally required or tolerated at low expression levels, but become toxic when present at high levels. The present study does not rule out this hypothesis, particularly when CAs were detected also in extracellular space. 
Nevertheless, the amounts of CAs in CW, as well as in cytosolic and mitochondrial fractions were so low that they had to be immunoprecipitated, in order to enable unambiguous and reproducible detection. C. albicans CW proteome has been a subject of many analyses in past [16], and CaNce103p has not occurred among the detected proteins, probably due to its low concentration. Therefore, it seems more likely that $\mathrm{CW}$ localization of $\mathrm{CAs}$ plays a specific role in ambient $\mathrm{CO}_{2}$ sensing and yeast growth. The $\mathrm{CO}_{2}$ fixed as $\mathrm{HCO}_{3}{ }^{-}$represents important substrate for carboxylation reactions occurring in different metabolic reactions that sustain gluconeogenesis, fatty acid elongation, tricarboxylic acid cycle, replenish $\mathrm{C}_{4}$ intermediates, etc. This opens an important question whether the $\mathrm{CO}_{2}$ hydrating and potentially also $\mathrm{CO}_{2}$ sensing role of $\mathrm{CAs}$ is impaired by the antimycotics targeting the $\mathrm{CW}$, such as echinocandins.

Proteomic analyses of mitochondria have not detected CaNce103 either [17], although mitochondrial localization of this CA has been suggested by Candida Genome Database, based on the localization of homologous $S$. cerevisiae enzyme in mitochondrial intermembrane space [18]. The present analysis detected CaNce103p as well as CpNce103p in mitochondrial fractions. Mitochondrial localization indicates involvement of the yeast $\mathrm{CAs}$ in hydrating intracellular $\mathrm{CO}_{2}$, arising from metabolic processes. While this study investigated the localization of CAs under one set of conditions, it would be interesting to examine whether changes of the carbon source can bring about changes in the CA localization

CaNce103p and CpNce103p have been detected also in cytosol. This is paralleled by the cytosolic localization of CA from S. cerevisiae [19]. The question is whether the occurrence of CaNce103p and CpNce103p in cytosol is transient, as they are being transported to other parts of the cells, or if these CAs are ubiquitous enzymes playing different roles at different cellular sites: sensing and hydrating $\mathrm{CO}_{2}$ regardless of whether it comes from the environment, or is formed during the metabolic reactions inside the cell.

\section{Materials and Methods}

\subsection{Strains and Growth Conditions}

C. albicans strain HE169 and C. parapsilosis strain P69 were obtained from the mycological collection of the Faculty of Medicine, Palacky University, Olomouc, Czech Republic. The yeasts were streaked on YPD ( $2 \%$ peptone, $1 \%$ yeast extract, $2 \%$ glucose $)$ agar and incubated at $30{ }^{\circ} \mathrm{C}$ for $24 \mathrm{~h}$. Single colonies were picked to inoculate $10 \mathrm{~mL}$ of YPD as a preculture. An aliquot $(200 \mu \mathrm{L})$ of the stationary phase preculture was then inoculated into $500 \mathrm{~mL}$ of YPD medium and cultivated in the rotation shaker at $250 \mathrm{rpm}$ and $30^{\circ} \mathrm{C}$.

\subsection{Immunogold Labeling and Electron Microscopy}

Immunogold labeling was performed using rabbit polyclonal antibodies (Moravian-Biotechnology, Brno, Czech Republic), which were raised against recombinant CpNce103p expressed in Escherichia coli and purified, as described by Dostál et al. [10]. These antibodies interacted with both CpNce103p and CaNce103p. Samples for EM analysis were prepared by cultivation of the yeasts in YPD at $30^{\circ} \mathrm{C}$ overnight. Cells were harvested by centrifugation (5000 $\mathrm{g}$ for $15 \mathrm{~min})$, and mixed with dextran in PBS buffer $\mathrm{pH} 7.4$ up to its final concentration of $20 \%$. The samples were immediately fast frozen by Leica EM PACT2 High Pressure Freezer (Leica-Microsystems, Vienna, Austria). Freeze substitution was carried out using a Leica EM AFS apparatus (Leica-Microsystems, Vienna, Austria) in dry acetone containing $0.5 \%$ uranyl acetate for $8 \mathrm{~h}$ and sequences of $-90,-70$, and $-50{ }^{\circ} \mathrm{C}$. The samples were washed, infiltrated into Lowicryl HM20 resin and polymerized with UV radiation. Ultrathin sections $(70 \mathrm{~nm})$ prepared on ultramicrotome (Leica Ultracent EM UC7, Leica-Microsystems, Vienna, Austria)) were mounted on parlodion-coated nickel grids, which were subsequently blocked for 25 minutes using the buffer consisting of $1 \%$ BSA $(w / v)$ in PBS, pH 7.4 and $10 \%$ normal goat serum $(v / v)$ and incubated in buffer A $(0.5 \%$ BSA $(w / v), 0.05 \%$ TWEEN $20(v / v)$ in PBS, pH 7.4) containing anti-CpNce103p 
antibody diluted 1:100, overnight at $4{ }^{\circ} \mathrm{C}$. After washing with buffer $\mathrm{A}$, the grids were treated with a droplet of goat anti-rabbit IgG conjugated to $10 \mathrm{~nm}$ gold particles (British Biocell, Cardiff, UK), diluted 1:25 in buffer $\mathrm{A}$, and incubated for $1 \mathrm{~h} 4{ }^{\circ} \mathrm{C}$. Then, the grids were washed, stained with uranyl acetate, and viewed with a JEOL JEM 1011 electron microscope at $80 \mathrm{kV}$ (JEOL Europe SAS, Croissy sur Seine, France).

\subsection{Isolation of the Cell Wall}

Cell wall (CW) and plasma membrane (PM) fractions were prepared based on the protocols described by Zinser and Daum and Pitarch et al. [14,20]. Brifly, Candida cells were harvested by centrifugation at $4000 \times g$ for 10 minutes, resuspended in $30 \mathrm{mM}$ TRIS, $50 \mathrm{mM}$ ammonium acetate, pH 8.5, supplemented with $5 \mathrm{mM}$ EDTA and $0.5 \mathrm{mM}$ PefaBloc (Sigma-Aldrich, St. Louis, MO, USA), disintegrated using EmulsiFlex-C3 homogenizer (Biopharma Group, Dublin, Republic of Ireland) and brief sonication, and centrifuged at $2000 \times g$ for 10 minutes. The sediment containing the crude $\mathrm{CW}$ was washed five times with each of the following solutions: ice-cold $5 \% \mathrm{NaCl}, 2 \% \mathrm{NaCl}, 1 \% \mathrm{NaCl}$, and water. Supernatant was further centrifuged at $20,000 \times \mathrm{g}$ for $20 \mathrm{~min}$, yielding PM in sediment. $\mathrm{CW}$ and PM were resuspended in $50 \mathrm{mM}$ Tris- $\mathrm{HCl}$, pH 7.5 containing 2\% SDS, $0.1 \mathrm{M}$ EDTA, $40 \mathrm{mM}$ $\beta$-mercaptoethanol. To release the proteins, the suspensions were heated to $100{ }^{\circ} \mathrm{C}$ for $5 \mathrm{~min}$ and then centrifuged $(5 \mathrm{~min} 2000 \times \mathrm{g}$ ). The supernatants were dialyzed against $50 \mathrm{mM}$ Tris- $\mathrm{Cl}, 150 \mathrm{mM} \mathrm{NaCl}$, pH 7.5 [21].

\subsection{Mass Spectrometry Analysis of Nce103p in the Cell Wall Samples}

CAs potentially localized in $\mathrm{CW}$ and $\mathrm{PM}$ were immunoprecipitated using polyclonal anti-CpNce103p antibodies bound to Protein A Mag Sepharose ${ }^{\mathrm{TM}}$ beads (GE Healthcare) using the manufacturer's procedure. A negative control without antibodies was also prepared. The antibody-cross-linked beads were incubated overnight at $4{ }^{\circ} \mathrm{C}$ with $600 \mu \mathrm{L}$ solution of proteins released from PM and CW. After incubation, the immunoprecipitated proteins were washed with TBS buffer (50 mM Tris-Cl, $150 \mathrm{mM} \mathrm{NaCl} \mathrm{pH} 7.5$ ) five times, and eluted with $50 \mu \mathrm{L}$ of $0.1 \mathrm{M}$ glycine- $\mathrm{HCl}, \mathrm{pH} 2.9$, containing $2 \mathrm{M}$ urea and subjected to Western blotting using polyclonal antibodies against $\mathrm{CpNce103p}$ and mass-spectrometry (MS) analysis. Proteins for MS were either reduced on the magnetic beads by dithiothreitol and alkylated by iodoacetamide or left in their native form and then digested by trypsin overnight at $\mathrm{pH}$ 8.5. Desalted peptides eluted from Acclaim PepMap100 column were analyzed using UltiMate 3000 RSLCnano system (Thermo Fisher Scientific, Waltham, MA, USA 02451) coupled to Orbitrap Fusion Lumos (Thermo Fisher Scientific, MA, USA, 02451) using orbitrap in both MS and MSMS acquisition steps in range 100-2000 m/z. Protein identification was performed using the UniProt sequence database (CpNce103p, UniProtKB: G8B6R8 and CaNce130p, UniProtKB:Q5AJ71) with Proteome discoverer 2.3 software (Thermo Fisher Scientific, MA, USA).

\subsection{Preparation of Spheroplasts and Subcellular Fractions}

Mid-exponential phase Candida cells were harvested from YPD cultures by centrifugation at $4000 \times$ $g$ for $10 \mathrm{~min}$. The cells were washed with ice-cold $10 \mathrm{mM} \mathrm{NaN}_{3}$, resuspended in SPB buffer $(0.8$ $\mathrm{M}$ sorbitol, $40 \mathrm{mM} \beta$-mercaptoethanol, $50 \mathrm{mM} \mathrm{KH}_{2} \mathrm{PO}_{4}, \mathrm{pH}$ 7.5). The suspension was treated with Lyticase (Sigma-Aldrich, St. Louis, MO, USA) at a concentration of $1 \mathrm{mg} / 100 \mathrm{mg}$ wet biomass. The mixture was incubated at $30^{\circ} \mathrm{C}$ with shaking at $250 \mathrm{rpm}$ until the $\mathrm{OD}_{600}$ of the suspension dropped to at least $10 \%$ of its initial value. Then, the suspension was centrifuged at $1500 \times \mathrm{g}$ for $15 \mathrm{~min}$ at $4{ }^{\circ} \mathrm{C}$. Supernatant was used as lyticase-released cell wall proteins (LRP), and sediment containing spheroplasts was used for subcellular fractionation.

The harvested Candida spheroplasts were washed twice in $1 \mathrm{M}$ sorbitol and resuspended in ice-cold SPB buffer, supplemented with $1 \mathrm{mM}$ EDTA. Disintegration was performed by using Dounce homogenizer. The lysate was centrifuged at $2500 \times g$ and $4{ }^{\circ} \mathrm{C}$ in order to remove unbroken or partially disrupted cells and aggregates. The resulting supernatant was further centrifuged at $10,000 \times g$ for 30 
$\min , 4^{\circ} \mathrm{C}$. The supernatant was used as cytosolic fraction (CYT). The pellet was resuspended in $2 \mathrm{~mL}$ of buffer A (250 mM sucrose, $1 \mathrm{mM}$ EDTA, $10 \mathrm{mM}$ HEPES pH7.4) and layered on the top of a $10 \mathrm{mM}$ HEPES-buffered sucrose step gradient ( $2 \mathrm{~mL}, 15 \% ; 3 \mathrm{~mL}, 25 \% ; 3 \mathrm{~mL}, 40 \%$; and $2 \mathrm{~mL}, 60 \%$, respectively) and centrifuged for $1 \mathrm{~h}$ at $4^{\circ} \mathrm{C}$ at $100,000 \times g$ in a SW41Ti rotor (Beckman Coulter, Brea, CA, USA). A reddish-brown mitochondria-enriched layer was collected and used as a mitochondrial fraction (MIT).

\subsection{Western Blot Analysis of Subcellular Fractions}

MIT fraction (50 mg of protein dissolved in $50 \mu \mathrm{L}$ PLB buffer) was subjected to Western blotting analysis directly. LRP and CYT fractions were immunoprecipitated using anti-CpNce103 polyclonal antibodies. In a parallel experiment, proteins were immunoprecipitated using antibodies against peptide derived from the mitochondrial ATP synthase (anti-ATP5A; Abcam, Cambridge, UK), to provide a control of potential contamination of LRP and CYT by mitochondria. The antibodies were bound to Protein A Mag Sepharose TM (GE Healthcare, Chicago, IL, USA) beads using the manufacturer's procedure. The negative control without antibodies was prepared similarly. The ready antibody-cross-linked beads were incubated overnight at $4{ }^{\circ} \mathrm{C}$ with $5 \mathrm{~mL}$ of CYT and LRP, in which the protein concentration was adjusted approximately to $10 \mathrm{mg} / \mathrm{mL}$. After incubation, the beads with immunoprecipitated proteins were washed with TBS buffer (50 mM Tris- $\mathrm{Cl}, 150 \mathrm{mM} \mathrm{NaCl} \mathrm{pH} \mathrm{7.5)} \mathrm{five}$ times and resuspended in $50 \mu \mathrm{L}$ of PLB buffer (4\% SDS, 10\% 2-mercaptoethanol, 20\% glycerol, $0.004 \%$ bromophenol blue, $0.125 \mathrm{M}$ Tris- $\mathrm{HCl}$ pH 6.8). Analyzed proteins were separated on $12 \%$ SDS-PAGE gel, blotted on nitrocellulose membrane and detected by using polyclonal anti-CpNce103p or anti-ATP5A antibodies (Abcam, Cambridge, UK). Peroxidase-labeled swine anti-rabbit immunoglobulins were used as the secondary antibodies, and the visualization was performed using the West Femto detection system (Thermo Fisher Scientific, Waltham, MA, USA). Band intensities for CaNce103p and CpNce103p were analyzed using a Typhoon system and ImageQuant software (Amersham Biosciences, version TL 8.1, Little Chalfont, UK).

\section{Conclusions}

We used several methods to demonstrate that the Nce103p CAs of C. albicans and C. parapsilosis are predominantly localized in the cell wall and plasma membrane but partially also in the cytoplasm and mitochondria, suggesting important role of $\mathrm{CAs}$ in $\mathrm{CO}_{2}$ sensing and regulation of bicarbonate level for intracellular carboxylation reactions.

Supplementary Materials: Supplementary materials can be found at http://www.mdpi.com/1422-0067/21/3/850/s1. Author Contributions: J.D., O.H., I.P. participated in research design. J.D., J.B., R.H., M.H., O.H. performed the experiments, J.D., R.H., M.H., O.H. analyzed the data, O.H., I.P. supervised the study. J.D., O.H., I.P. wrote the original draft of the manuscript and all authors reviewed and approved the final manuscript. All authors have read and agreed to the published version of the manuscript.

Funding: This work was supported by grant GA17-08343S from the Czech Science Foundation.

Acknowledgments: The authors would like to thank to Mrs. Elena Dolejší for the assistance with subcellular fractionations.

Conflicts of Interest: The authors declare no conflict of interest.

\section{References}

1. Guinea, J. Global trends in the distribution of Candida species causing candidemia. Clin. Microbiol. Infect. 2014, 8, 5-10. [CrossRef] [PubMed]

2. Ben-Ami, R. Treatment of invasive candidiasis: A narrative review. J. Fungi 2018, 4, 97. [CrossRef] [PubMed]

3. Tóth, R.; Nosek, J.; Mora-Montes, H.M.; Gabaldon, T.; Bliss, J.M.; Nosanchuk, J.D.; Turner, S.A.; Butler, G.; Vágvölgyi, C.; Gácser, A. Candida parapsilosis: From Genes to the Bedside. Clin. Microbiol. Rev. $2019,32$. [CrossRef] [PubMed] 
4. $\quad$ Klengel, T.; Liang, W.-J.J.; Chaloupka, J.; Ruoff, C.; Schröppel, K.; Naglik, J.R.; Eckert, S.E.; Mogensen, E.G.; Haynes, K.; Tuite, M.F.; et al. Fungal adenylyl cyclase integrates CO2 sensing with cAMP signaling and virulence. Curr. Biol. 2005, 15, 2021-2026. [CrossRef] [PubMed]

5. Segal, E.S.; Gritsenko, V.; Levitan, A.; Yadav, B.; Dror, N.; Steenwyk, J.L.; Silberberg, Y.; Mielich, K.; Rokas, A.; Gow, N.A.R.; et al. Gene Essentiality Analyzed by In Vivo Transposon Mutagenesis and Machine Learning in a Stable Haploid Isolate of Candida albicans. MBio 2018, 9. [CrossRef] [PubMed]

6. Cottier, F.; Raymond, M.; Kurzai, O.; Bolstad, M.; Leewattanapasuk, W.; Jiménez-López, C.; Lorenz, M.C.; Sanglard, D.; Váchová, L.; Pavelka, N.; et al. The bZIP transcription factor Rca1p is a central regulator of a novel CO 2 sensing pathway in yeast. PLoS Pathog. 2012, 8. [CrossRef] [PubMed]

7. Martin, R.; Pohlers, S.; Mühlschlegel, F.A.; Kurzai, O. CO2 sensing in fungi: At the heart of metabolic signaling. Curr. Genet. 2017, 63, 965-972. [CrossRef] [PubMed]

8. Elleuche, S.; Pöggeler, S. Carbonic anhydrases in fungi. Microbiology 2010, 156, 23-29. [CrossRef] [PubMed]

9. Teng, Y.-B.; Jiang, Y.-L.; He, Y.-X.; He, W.-W.; Lian, F.-M.; Chen, Y.; Zhou, C.-Z. Structural insights into the substrate tunnel of Saccharomyces cerevisiae carbonic anhydrase Nce103. BMC Struct. Biol. 2009, 9, 67. [CrossRef] [PubMed]

10. Dostál, J.; Brynda, J.; Blaha, J.; Macháček, S.; Heidingsfeld, O.; Pichová, I. Crystal structure of carbonic anhydrase CaNce103p from the pathogenic yeast Candida albicans. BMC Struct. Biol. 2018, 18. [CrossRef] [PubMed]

11. Götz, R.; Gnann, A.; Zimmermann, F.K. Deletion of the carbonic anhydrase-like geneNCE103 of the yeastSaccharomyces cerevisiae causes an oxygen-sensitive growth defect. Yeast 1999, 15, 855-864. [CrossRef]

12. Cleves, A.E.; Cooper, D.N.W.; Barondes, S.H.; Kelly, R.B. A new pathway for protein export in Saccharomyces cerevisiae. J. Cell Biol. 1996, 133, 1017-1026. [CrossRef] [PubMed]

13. Skrzypek, M.; Binkley, J.; Binkley, G.; Miyasato, S.; Simison, M.; Sherlock, G. Candida Genome Database. Available online: http://www.candidagenome.org/ (accessed on 20 January 2020).

14. Zinser, E.; Daum, G. Isolation and biochemical characterization of organelles from the yeast, Saccharomyces cerevisiae. Yeast 1995, 11, 493-536. [CrossRef] [PubMed]

15. Petersen, T.N.; Brunak, S.; Von Heijne, G.; Nielsen, H. SignalP 4.0: Discriminating signal peptides from transmembrane regions. Nat. Methods 2011, 8, 785-786. [CrossRef] [PubMed]

16. Klis, F.M.; Brul, S. Adaptations of the secretome of Candida albicans in response to host-related environmental conditions. Eukaryot. Cell 2015, 14, 1165-1172. [CrossRef] [PubMed]

17. She, X.; Zhang, P.; Gao, Y.; Zhang, L.; Wang, Q.; Chen, H.; Calderone, R.; Liu, W.; Li, D. A mitochondrial proteomics view of complex I deficiency in Candida albicans. Mitochondrion 2018, 38, 48-57. [CrossRef] [PubMed]

18. Vögtle, F.N.; Burkhart, J.M.; Rao, S.; Gerbeth, C.; Hinrichs, J.; Martinou, J.C.; Chacinska, A.; Sickmann, A.; Zahedi, R.P.; Meisinger, C. Intermembrane space proteome of yeast mitochondria. Mol. Cell. Proteomics 2012, 11, 1840-1852. [CrossRef] [PubMed]

19. Kumar, A.; Agarwal, S.; Heyman, J.A.; Matson, S.; Heidtman, M.; Piccirillo, S.; Umansky, L.; Drawid, A.; Jansen, R.; Liu, Y.; et al. Subcellular localization of the yeast proteome. Genes Dev. 2002, 16, 707-719. [CrossRef] [PubMed]

20. Pitarch, A.; Sánchez, M.; Nombela, C.; Gil, C. Sequential fractionation and two-dimensional gel analysis unravels the complexity of the dimorphic fungus Candida albicans cell wall proteome. Mol. Cell. Proteomics 2002, 1, 967-982. [CrossRef] [PubMed]

21. Vinterová, Z.; Šanda, M.; Dostál, J.; Hrušková-Heidingsfeldová, O.; Pichová, I. Evidence for the presence of proteolytically active secreted aspartic proteinase 1 of Candida parapsilosis in the cell wall. Protein Sci. 2011, 20, 2004-2012. [CrossRef] [PubMed]

(C) 2020 by the authors. Licensee MDPI, Basel, Switzerland. This article is an open access article distributed under the terms and conditions of the Creative Commons Attribution (CC BY) license (http://creativecommons.org/licenses/by/4.0/). 